\title{
A case of large right MCA stroke with hyperdense MCA sign in CT imaging
}

Dileep Unnikrishnan, ${ }^{1}$ Srujana Yada, ${ }^{1}$ Noah Gilson ${ }^{2}$

${ }^{1}$ Internal Medicine, Monmouth Medical Center, Long Branch, New Jersey, USA

${ }^{2}$ Neurology, Monmouth Medical Center, Long Branch, New Jersey, USA

\section{Correspondence to} Dr Dileep Unnikrishnan, drdileepunni@gmail.com

Accepted 15 November 2017

\section{DESCRIPTION}

A 76-year-old woman with no significant medical history was brought to the emergency department with complaints of sudden onset of left-sided weakness and facial drooping 1 hour prior to the arrival. On physical examination, patient had profound left-sided neglect and conjugate deviation of the eyes to the right side. Motor examination showed grade 0 power on left upper and lower extremities, and she had $3+$ reflexes on the left and $2+$ reflexes on the right. Babinski was positive on the left side. She was sent for a CT scan which showed increased density of M1 segment of middle cerebral artery (MCA) with loss of grey white differentiation of MCA territory (figure 1). Alberta Stroke Programme Early CT Score was 8. Patient's initial National Institutes of Health Stroke Scale score was 17 and was immediately given tissue plasminogen activator (TPA) as the family adamantly refused endovascular procedure; however, her post-TPA score was also 17 as she showed no signs of improvement. She was taken for MRI of brain which showed diffusion restriction of right basal ganglia (figure 2) consistent with

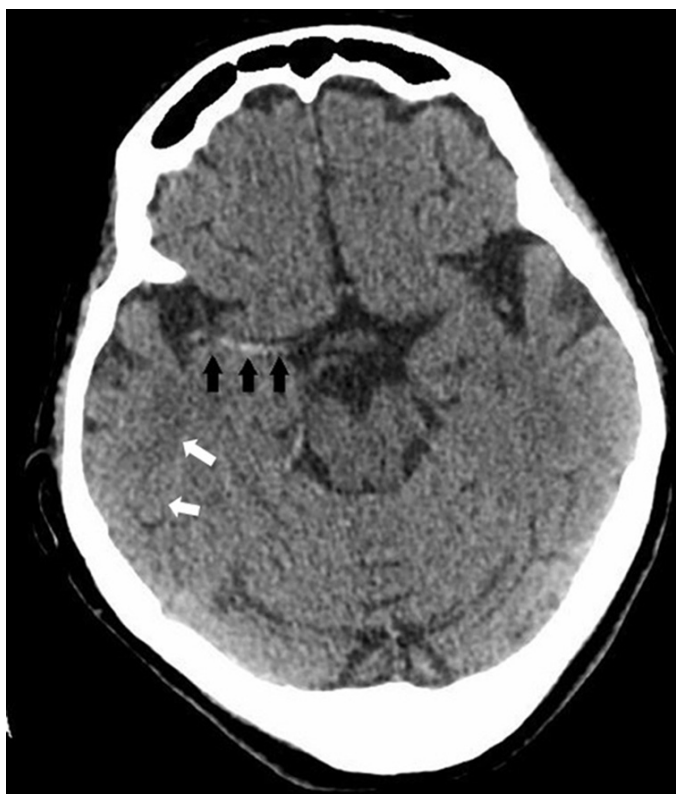

Figure 1 Non-contrast CT done on presentation to the emergency department shows increased density in the middle cerebral artery (MCA, black arrows) with loss of grey white differentiation of MCA territory (white arrows).

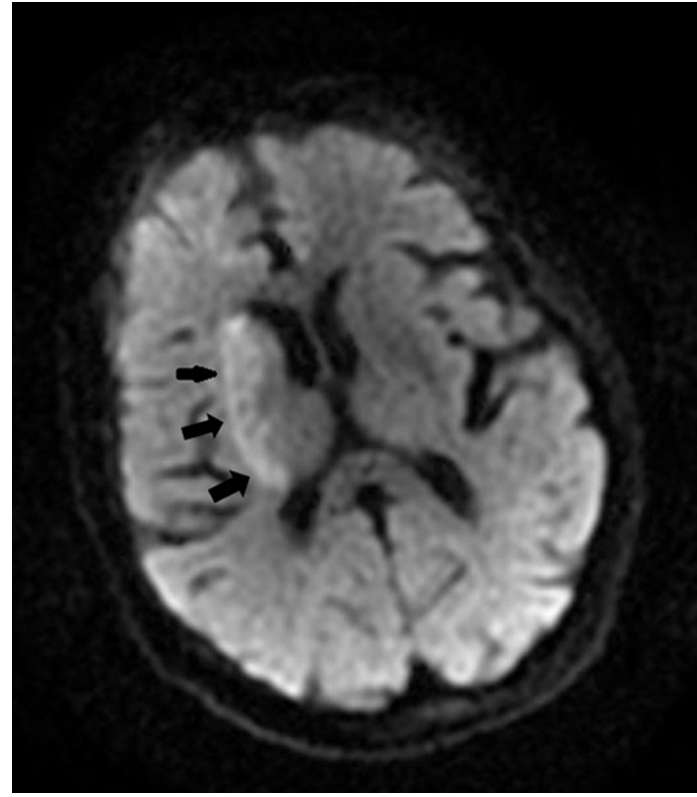

Figure 2 MRI brain diffusion-weighted imaging shows diffusion restriction in right basal ganglia (black arrows) suggestive of acute infarct.

acute infarct. T2-weighted imaging along with T2/fluid-attenuated inversion recovery did not show increased signal in the corresponding

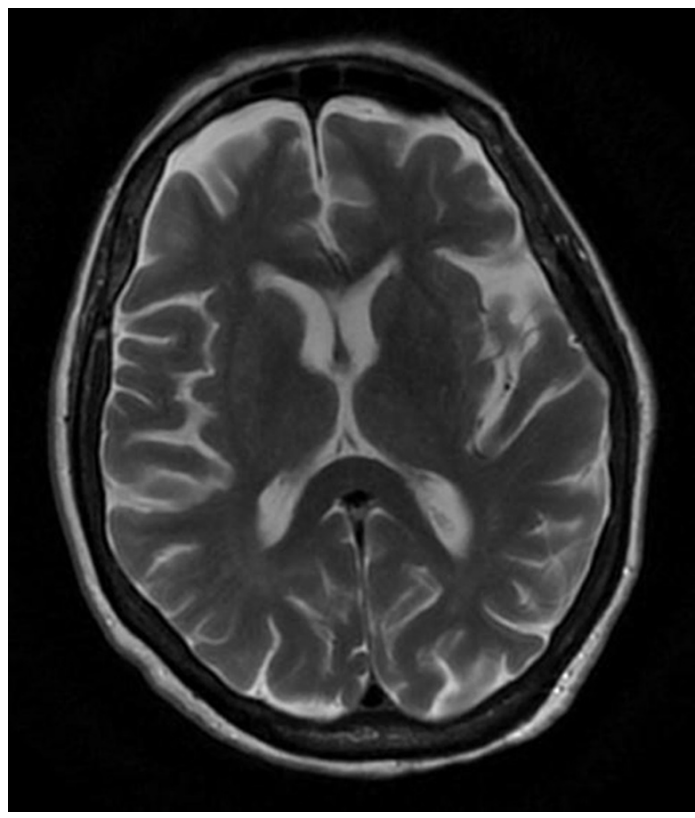

Figure 3 T2-weighted imaging of MRI brain which does not show increased signalling in the area corresponding to the infarct in diffusion-weighted imaging. 


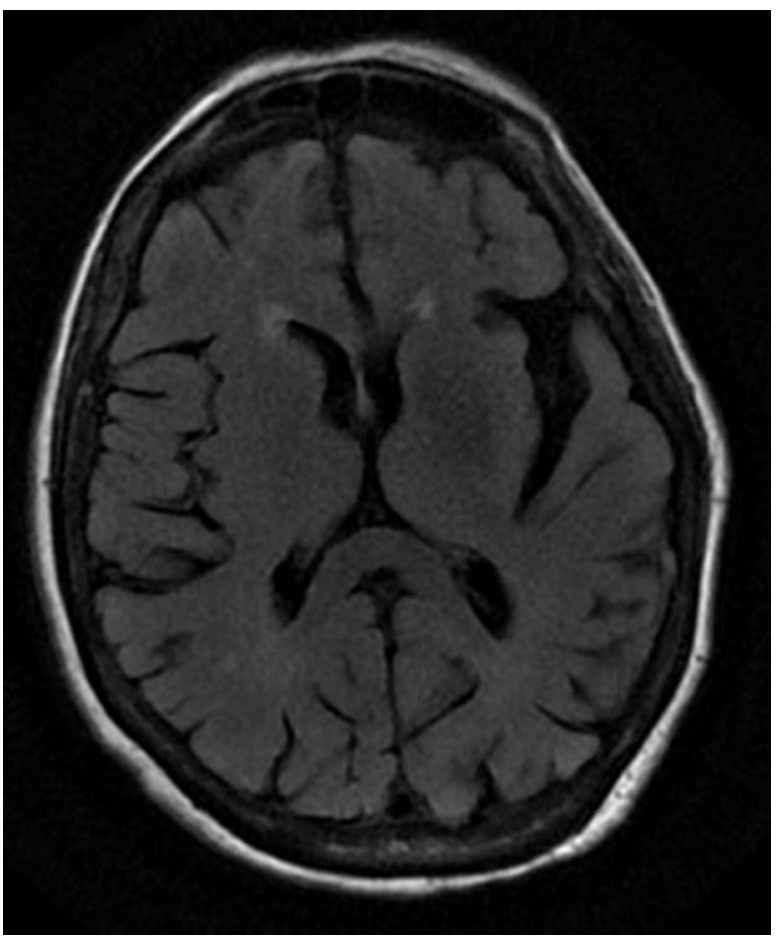

Figure 4 T2/fluid-attenuated inversion recovery imaging of MRI brain which does not show increased signalling in the area corresponding to the infarct in diffusion-weighted imaging.

region (figures 3 and 4). Magnetic resonance angiogram of head showed marked attenuation of the M1 segment of the right MCA (figure 5). As the patient was not improving

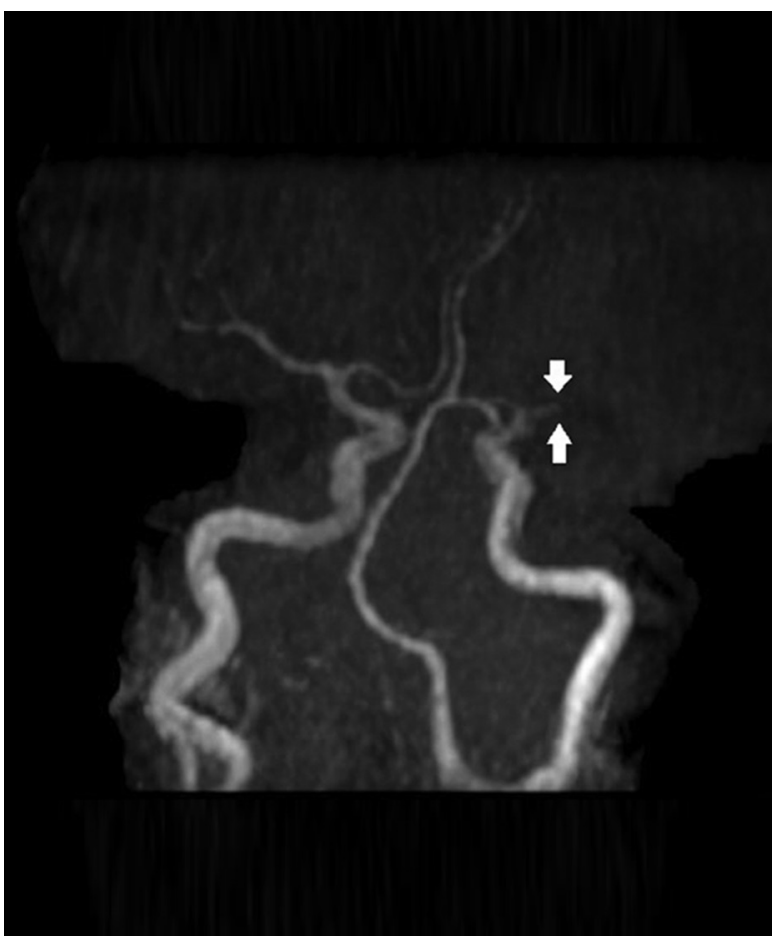

Figure 5 Magnetic resonance angiogram of head showing marked attenuation of M1 segment of right middle cerebral artery (white arrows) with markedly diminished blood flow distally.

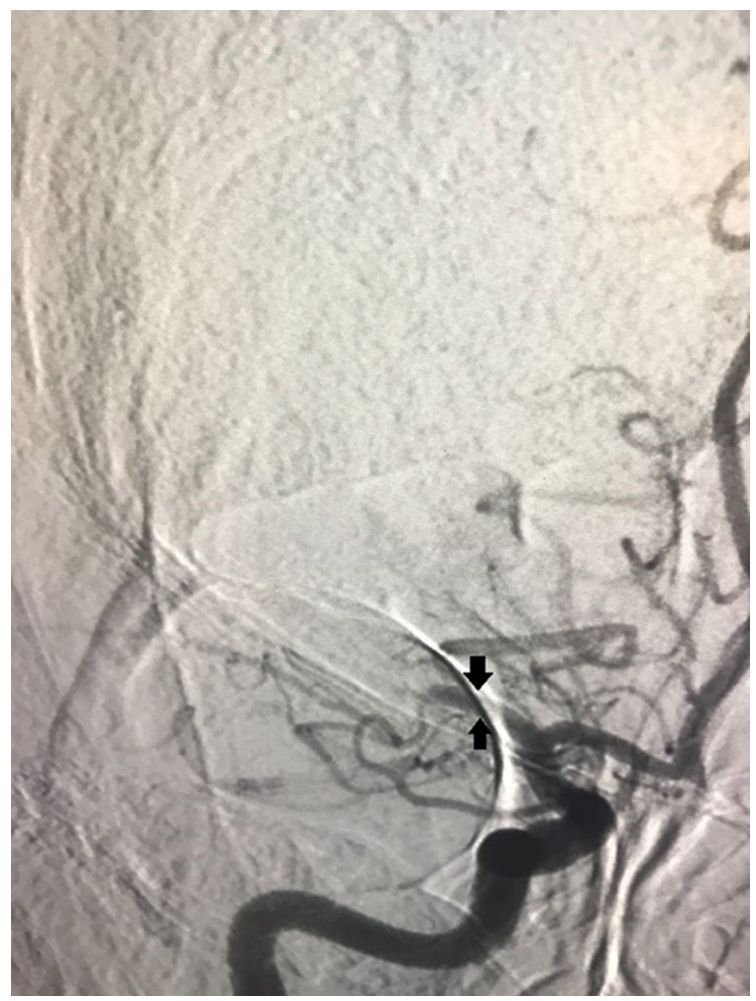

Figure 6 Angiogram of head during intravascular thrombectomy showing restricted blood flow through $\mathrm{M} 1$ segment of right middle cerebral artery (black arrows).

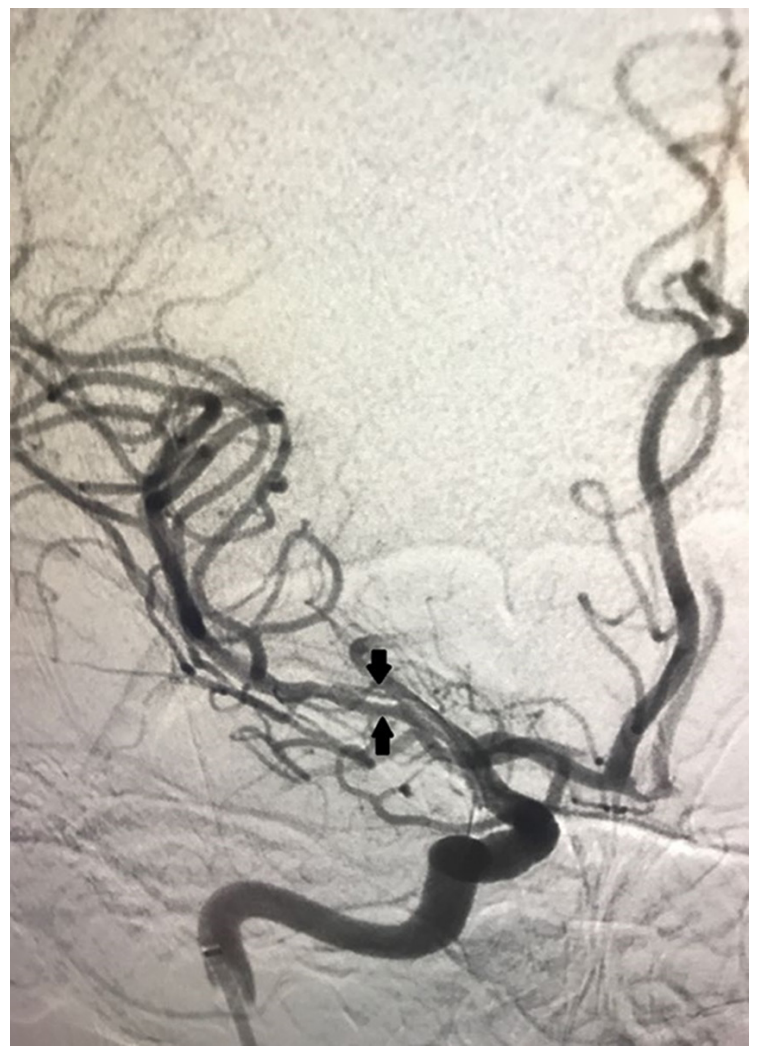

Figure 7 Angiogram postintravascular thrombectomy showing restoration of flow through right middle cerebral artery (black arrows). 


\section{Learning points}

- CT of head without contrast is done in all patients who present with symptoms of stroke in an emergency department. While this investigation is commonly used to rule out acute intracranial haemorrhage, in cases of ischaemic strokes involving larger vessels, subtle changes can be seen even in a CT non-contrast study. Subtle blurring and decreased attenuation of grey white junction due to oedema is the most common early finding in such studies. As the stroke evolves, the parenchymal hypoattenuation increases. ${ }^{1}$ Hyperintensity in diffusion-weighted imaging is the earliest change detectable in MRI, followed by high-signal intensity in T2/fluid-attenuated inversion recovery, which is evident 6 hours postinsult. Absent or reduced flow on magnetic resonance angiogram imaging on the involved arteries is also seen early in cases of ischaemic stroke. ${ }^{2}$

- The increased density of middle cerebral artery (MCA) on head non-contrast CT is referred to as hyperdense MCA sign. Hyperdensity of the vessel is due to large intravascular clots and if present is the earliest sign on imaging in cases of large MCA strokes.

- This sign is highly sensitive for large ischaemic MCA strokes and can aid in quick diagnosis and prompt intervention. ${ }^{3}$ In such conditions with large territories of brain is involved, tissue plasminogen activator is not very effective, and resorting to endovascular thrombectomy within the window period can result in much better neurological outcome. ${ }^{3}$ with intravenous TPA, family decided to go ahead with endovascular thrombectomy, and she was immediately taken for the procedure. The clot was removed within the 8-hour window period, and the prethrombectomy and post-thrombectomy images showed good improvement of right MCA flow (figures 6 and 7). She did not show marked improvement in her neurological function immediately following the procedure. However, she showed significant improvement in functional status at 2-week follow-up.

Contributors All authors were involved firsthand in the care of the patient and in preparing the images and the report.

Competing interests None declared.

Patient consent Obtained.

Provenance and peer review Not commissioned; externally peer reviewed.

(c) BMJ Publishing Group Ltd (unless otherwise stated in the text of the article) 2017. All rights reserved. No commercial use is permitted unless otherwise expressly granted.

\section{REFERENCES}

1 Nakano $\mathrm{S}$, Iseda T, Kawano $\mathrm{H}$, et al. Correlation of early CT signs in the deep middle cerebral artery territories with angiographically confirmed site of arterial occlusion. AJNR Am J Neuroradiol 2001;22:654-9.

2 Allen LM, Hasso AN, Handwerker J, et al. Sequence-specific MR imaging findings that are useful in dating ischemic stroke. Radiographics 2012;32:1285-97.

3 Leys D, Pruvo JP, Godefroy 0 , et al. Prevalence and significance of hyperdense middle cerebral artery in acute stroke. Stroke 1992;23:317-24.

Copyright 2017 BMJ Publishing Group. All rights reserved. For permission to reuse any of this content visit http://group.bmj.com/group/rights-licensing/permissions.

BMJ Case Report Fellows may re-use this article for personal use and teaching without any further permission.

Become a Fellow of BMJ Case Reports today and you can:

- Submit as many cases as you like

- Enjoy fast sympathetic peer review and rapid publication of accepted articles

- Access all the published articles

- Re-use any of the published material for personal use and teaching without further permission

For information on Institutional Fellowships contact consortiasales@bmjgroup.com

Visit casereports.bmj.com for more articles like this and to become a Fellow 